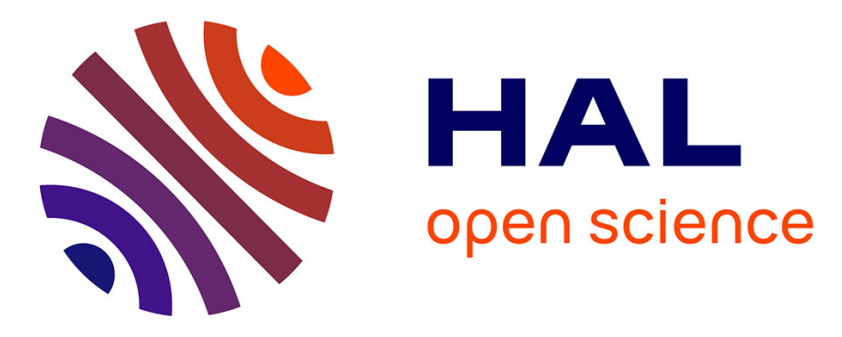

\title{
Effect of the hot rolling on Goss development and magnetic induction in an advanced soft magnetic Fe-27\% Co alloy
}

Brahim Nabi, Anne-Laure Helbert, Francois Brisset, Thierry Waeckerle, Rémy Batonnet, Thierry Baudin

\section{To cite this version:}

Brahim Nabi, Anne-Laure Helbert, Francois Brisset, Thierry Waeckerle, Rémy Batonnet, et al.. Effect of the hot rolling on Goss development and magnetic induction in an advanced soft magnetic Fe-27\% Co alloy. Journal of Alloys and Compounds, 2020, 834, pp.155149. 10.1016/j.jallcom.2020.155149 . hal03010604

\section{HAL Id: hal-03010604 https://hal.science/hal-03010604}

Submitted on 27 Nov 2020

HAL is a multi-disciplinary open access archive for the deposit and dissemination of scientific research documents, whether they are published or not. The documents may come from teaching and research institutions in France or abroad, or from public or private research centers.
L'archive ouverte pluridisciplinaire HAL, est destinée au dépôt et à la diffusion de documents scientifiques de niveau recherche, publiés ou non, émanant des établissements d'enseignement et de recherche français ou étrangers, des laboratoires publics ou privés. 


\title{
Effect of the hot rolling on Goss development and magnetic induction in an advanced soft magnetic Fe-27\% Co alloy
}

\author{
Brahim Nabi ${ }^{\mathrm{a}}$, Anne-Laure Helbert ${ }^{\mathrm{a}}$, François Brisset ${ }^{\mathrm{a}}$, Thierry Waeckerléb ${ }^{\mathrm{b}}$, Rémy Batonnet ${ }^{\mathrm{b}}$, \\ Thierry Baudina \\ ${ }^{a}$ ICMMO, SP2M, Univ. Paris-Sud, Université Paris-Saclay, UMR CNRS 8182, 91405 Orsay Cedex, France \\ ${ }^{b}$ Aperam alloys Imphy, 58160, Imphy, France.
}

Corresponding Author: Anne-Laure Helbert, anne-laure.helbert@u-psud.fr

\begin{abstract}
This paper shows a complete study about the characterization of the texture and the microstructure evolution of an industrial thermo-mechanical processing aiming to develop an advanced soft magnetic Fe-27\% Co material with a sharp Goss texture. Thanks to its high magnetic performances, this alloy is able to replace the grain oriented Fe-Si alloy in transformers of electric aircrafts application.

It appears that the development of a highly Goss textured Fe-27\%Co alloy could be achieved by optimizing the intensity of the Goss and rotated Cube texture during hot rolling using an adequate thermo-mechanical processing, namely finishing hot rolling in the ferritic phase.
\end{abstract}

Keywords: Fe-27\%Co alloy, Hot rolling, Goss texture, Magnetic induction

\section{Introduction}

Due to the increase of the electric loads, the need of power and number of transformers in the aircrafts increases. This implies a growing demand for the aircraft industry to reduce the noise emitted by such equipment. This noise is due to the magnetostriction phenomenon and electromagnetic forces in the magnetic sheets. The magnetostriction, which is defined as a change of material shape or dimensions during the process of magnetization, is a consequence of magnetocrystalline anisotropy partly linked to the sheet crystallographic texture. A Fe-27\% Co alloy, denominated industrially AFK1, has been existing for a long time and is devoted to magnetic circuit of aeronautic generators. This material brings high power density in airborne electrical engineering, saving precious masses during flights. Such performances of AFK1 are based on its physical advantages, which the main ones are a high saturation magnetization value $(2.38 \mathrm{~T})$ and rather good magnetic properties (coercive field, permeability) at the same level as FeSi N.O. (Non Oriented) electrical steel. The interest of AFK1 remains high despite its drawbacks: rather high value of magnetocrystalline constant (K1 of about 45 $\mathrm{kJ} / \mathrm{m} 3)$, rather high apparent saturation magnetostriction $(\sim 35 \mathrm{ppm})$ and rather high cost. The usual AFK1 grade exhibits low texture components, then a weakly anisotropic magnetic behaviour at the macroscopic scale, well adapted to rotating electromagnetic machines. As electrical steels, it should be called AFK1 N.O.

As a continuation of Westinghous works in the 70s, Aperam Alloys Imphy develops new AFK1 grades, acting on the metallurgical route. The main one is based on the AFK1 ability to develop a Goss texture $(\{110\}<001>$ orientation), at the end of an adequate thermo-mechanical processing. If Goss texture is improved and if magnetic losses are further reduces, the AFK1 sheet should be able to get a place in the market of transportation transformers, requiring high power density, such as high speed train, large-scale machines in civil engineering or manufacturing, where Fe-3\%Si Grain Oriented grades are currently used.

The Goss texture offers the best magnetic properties necessary for such application [1-2] since high quantity of $\langle 100\rangle$ crystallographic axes (easy magnetization direction) are aligned in the sheet rolling direction. Therefore, a good understanding of the origin and the development of the Goss texture in the different steps of the industrial processing of the AFK1 is necessary for the optimization of its magnetic properties. 
The origin of the Goss texture obtained after recrystallization during the Goss industrial processing [3] of the grain oriented $\mathrm{Fe}-3 \% \mathrm{Si}$ alloy was widely investigated [1-14]. On one hand, many investigations on single or poly crystal of $\mathrm{Fe}-\mathrm{Si}$ alloy showed that the Goss texture of the primary recrystallization develops by the inheritance of this texture from hot rolling $[4,11]$. In fact, the Goss orientation present after hot rolling turn into the $\{111\}<112>$ component during cold rolling and then reappear during the primary recrystallization.

On the other hand, other investigations have shown that the origin of the Goss texture of the primary recrystallization in $\mathrm{Fe}$-Si alloys may derive from two types of Goss texture. By using EBSD technic, Dorner et al. [12] studied the evolution of the Goss texture in a single crystal of $\mathrm{Fe}-\mathrm{Si}$ deformed to $89 \%$ oriented initially $\{110\}<001>$. They showed that the Goss component could come from either the inheritance of the Goss texture of the hot rolling or the strong cold deformation which involves the development of the Goss texture in the shear bands of the cold rolled microstructure. Later, in 2008, in a polycrystalline of Fe-3\% Si, Cruz-Gandarilla et al. [13] showed similar results. Besides, it has been shown that for steels, the finishing hot rolling temperature had a decisive influence on the textures produced $[15,16]$.

In this paper, the evolution of the Goss texture from the hot rolled state to the final heat treatment of the Fe-Co electrical sheet, has been investigated in order to optimize the final Goss volume fraction of the product. The link between Goss texture and rolling process parameters will be studied all along the thermo-mechanical transformation and especially the role of the finishing hot rolling temperature and the associated texture will be discussed.

\section{Material and experiments}

The industrial Iron-Cobalt alloy with 27\% (wt \%) cobalt and $0.5 \%$ of Chrome, called AFK1, was provided by Aperam Alloys Imphy. The forged state was followed by a hot rolling (HR) to a final thickness of $2 \mathrm{~mm}$. Six different hot rolling conditions (HR1 to HR6) were tested, they were numbered as a function of their magnetic induction. Then, the sheets underwent exactly the same thermomechanical route: a first annealing at $930^{\circ} \mathrm{C}$ (A1), followed by a first $70 \%$ cold rolling (CR1). An intermediate annealing at $930^{\circ} \mathrm{C}$ (A2) was then applied before a second $70 \%$ cold rolling (CR2). Finally, the double cold rolled sheets underwent three successive final annealing treatments at $930^{\circ} \mathrm{C}$ (A3, A4 and A5) enabling the primary recrystallization and the normal grain growth to improve the Goss texture development.

The local texture was carried out by EBSD and the global one was measured by X-Ray diffraction. EBSD results were collected using a scanning electron microscope Zeiss FEG SUPRA 55 $\mathrm{VP}$ operating at $20 \mathrm{kV}$ and equipped with the $\mathrm{OIM}^{\mathrm{TM}}$ system. EBSD component fractions were determined with a $15^{\circ}$ dispersion. The samples were firstly mechanically polished and then electropolished (Struers A2 solution) at $22{ }^{\circ} \mathrm{C}$, with a voltage of $15 \mathrm{~V}$ for $12 \mathrm{~s}$. X-ray data were collected from a Siemens system $\left(\mathrm{K}_{\alpha}\right.$ cobalt radiation) and the $\{110\},\{200\}$ and $\{112\}$ incomplete pole figures were recorded. The data were then analyzed using the arbitrarily defined cells (ADC) method implemented in the Labotex software to calculate the complete pole figures and the orientation distribution function (ODF).

\section{Results}

\section{a. Relationship between the texture and the magnetic properties.}

Figure 1 shows the evolution of the magnetic induction $\left(\mathrm{B}_{100 \mathrm{e}}\right)$ for sheets coming from various hot rolling conditions and the associated Goss fraction for two of them available for investigation. Induction and Goss fraction were measured after the last annealing A5. It appears that induction strongly depends on hot rolling conditions. Moreover, for this Fe-Co alloy, magnetic induction is correlated to the Goss intensity, as already reported in the literature for $\mathrm{Fe}-\mathrm{Si}$ alloys $[1,13]$. 


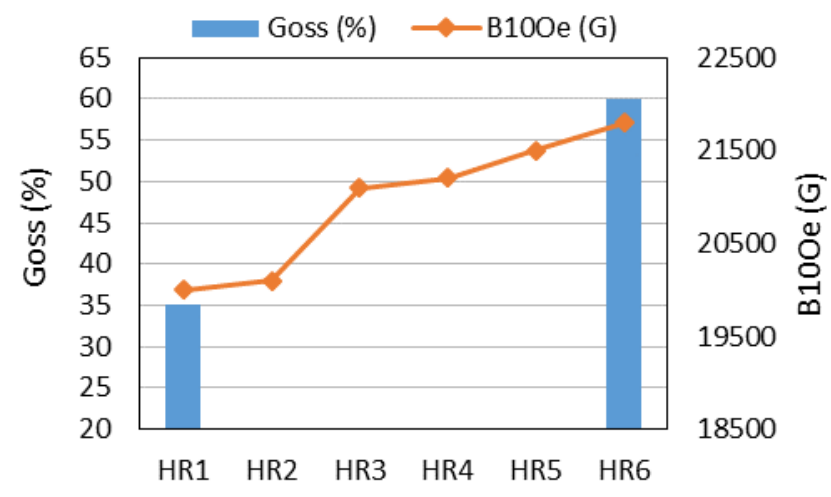

Figure 1: Evolution of the magnetic induction $B_{100 e}$ and Goss fraction of samples after $A 5$ annealing with different initial hot rolling conditions

\section{b. Texture evolution during the industrial elaboration process}

As Goss texture is conditioning the magnetic properties, it seem important to understand how the Goss texture develops during sheet elaboration. The texture evolution has been determined at each step of the thermomechanical process and ODFs sections are reported in figure 2 . This evolution has been characterized for samples HR1 and HR6, which correspond to extreme magnetic induction values among the samples, the lowest (HR1) and the highest (HR6). The A1 texture was measured by EBSD in the RD (Rolling Direction)-ND (Normal Direction) plan to study the texture gradient through thickness. The other states were characterized in the RD-TD (Transverse Direction) plan. Unfortunately, Aperam Alloys Imphy does not succeed to be sure about the hot rolling conditions of the samples, especially the finishing hot rolling temperatures. The latter have been sent by Aperam after the first annealing A1 for analyses.

(a)

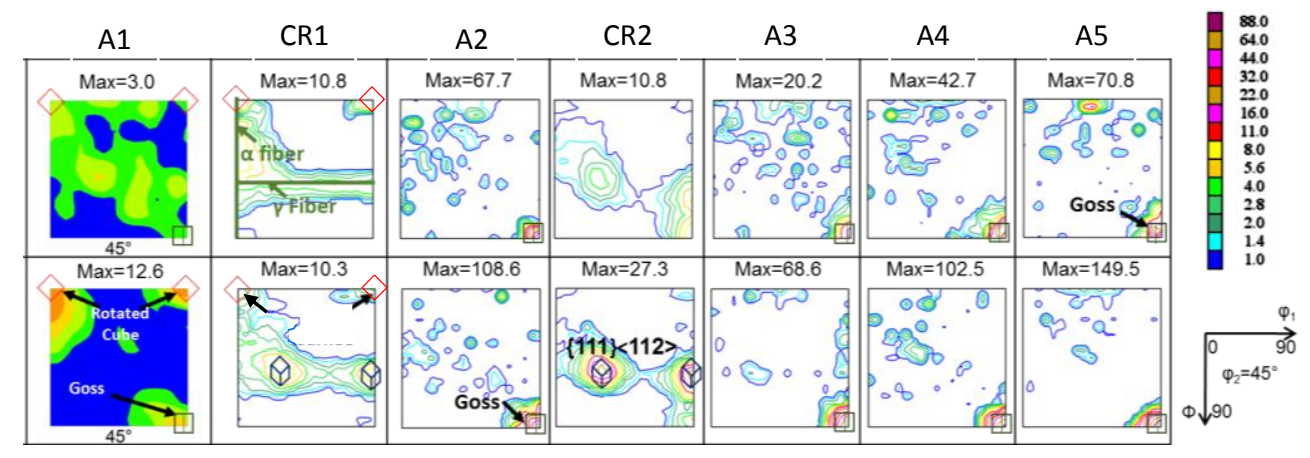

Figure 2: Texture evolution during the thermo-mechanical processing obtained by EBSD (A1) and by X-Ray diffraction of samples (a) HR1 and (b) HR6

After the first annealing at $930^{\circ} \mathrm{C}(\mathrm{A} 1)$, the $\mathrm{HR} 1$ texture is quasi-isotropic. On the contrary, HR6 is mainly characterized by a strengthening around the rotated Cube (18\%) and the Goss components $(9 \%)$. After the first cold rolling (CR1) to $70 \%$ thickness reduction, the texture of both samples is characterized by $\gamma$-fiber components $(\{111\} / /$ rolling plane $)$ and the presence of a partial $\alpha$ fiber $(<110>/ /$ rolling direction). The $\{111\}<112>$ component is more pronounced in the case of the sample derived from HR6. The second annealing at $930^{\circ} \mathrm{C}$ (A2) allows the development of the Goss component, which is more pronounced in the case of HR6. After the second cold rolling (CR2), the development of the $\{111\}<112\rangle$ component is once again observed. Finally, the final annealing treatments (A3, A4 and A5) lead to the development of the Goss texture and its strengthening. Then, after the final annealing A5, the Goss fraction coming from HR6 (60\%) is nearly twice that of the sample coming from HR1 (35\%). The HR6 hot rolling conditions are clearly more efficient to achieve a strong Goss texture and thus good magnetic properties. 
A comparison of both texture filiations (Figure 2) allows to note that only the first texture after A1 is notably different from a sample to the other. More, it appears that the final Goss intensity strongly depends on this initial texture. In order to better describe this A1 texture through the sheet thickness, a cross section of both sheets has been studied by EBSD.

First of all, a heterogeneity of grain size along the thickness of both sheets HR1 and HR6 is observed (Figure 3). Grain sizes of about 35 and $45 \mu \mathrm{m}$ at the center and 70 and $75 \mu \mathrm{m}$ at the surfaces are obtained for HR1 and HR6, respectively. This difference between center and surface grain size may be due to the shearing introduced by the mills during the hot rolling. Indeed, more stored energy in the shearing areas induces an acceleration of recrystallization and then of grain growth, while these last processes are delayed in the sheet center.

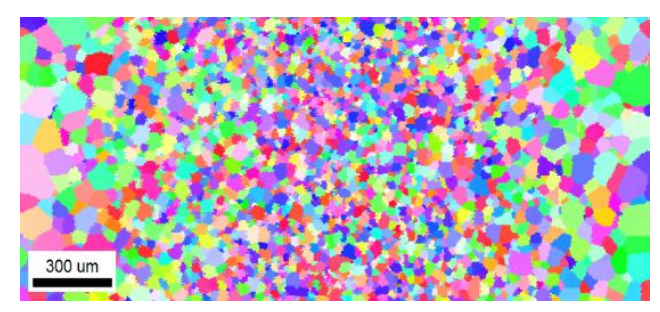

(a)

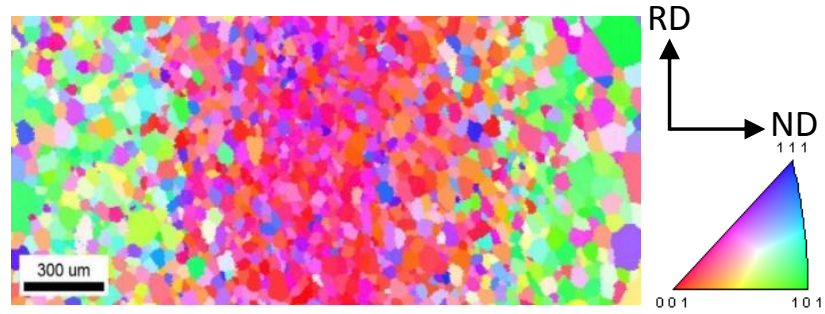

(b)

Figure 3: Microstructures of two hot rolled sheets after the first annealing A1 at $930^{\circ} \mathrm{C}$. (a) HR1, (b) HR6. ND-IPF maps.

More, as it can be clearly seen in Figure 3, texture of both samples after A1 is totally different depending on the hot rolled conditions. A quasi isotropic texture is obtained throughout the thickness of the sheet HR1, while the HR6 exhibits a heterogeneous texture: the mid-thickness of the sheet is characterized by a high intensity of the rotated Cube component while the surface is characterized by a domination of the Goss one (Figure 4).

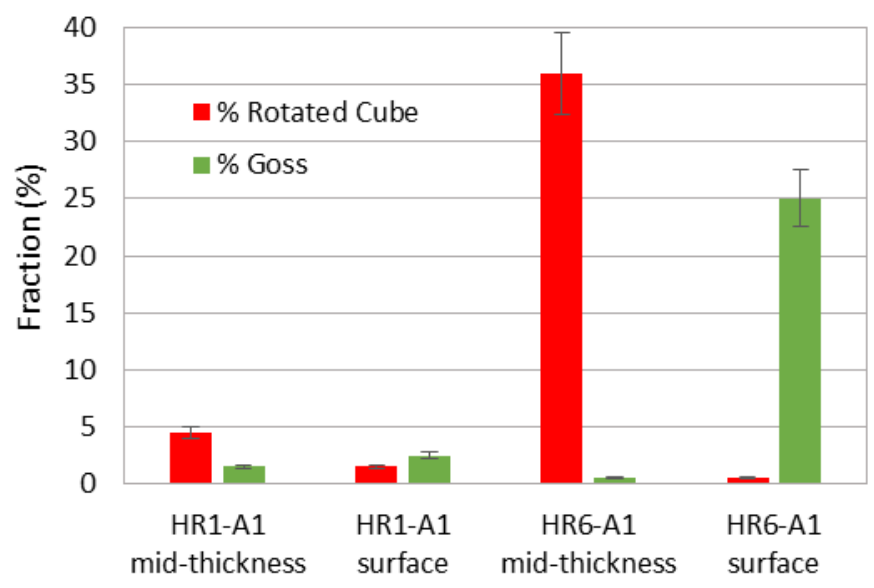

Figure 4: Texture heterogeneity through thickness in the HR1 and HR6 samples after first annealing A1.

Rotated Cube and Goss fractions are measured at the mid-thickness and at the surface of the sheets

As it is known from the literature, the rotated Cube texture is characteristic of hot rolling texture of bcc materials [7], which explains the development of such texture in the case of the Fe$27 \%$ Co alloy hot rolled. The Goss texture is characteristic of the shearing texture [1,7]. Nevertheless, as shown in Figure 4, the texture heterogeneity through thickness can be more or less pronounced depending on the hot rolling conditions. 


\section{Discussion}

Figure 5 shows the evolution of the main texture component fractions as a function of the thermo-mechanical stages, for the hot rolled samples HR1 and HR6 after A1. The thermo-mechanical history of these sheets is a sequence of peaks corresponding to the $\{111\}<112>$ orientation development during cold rolling and the Goss intensity increases during annealing treatments. Except after A1 for HR6 $(\approx 20 \%)$, the rotated Cube fraction is quite constant and lower than $10 \%$ during the different thermo-mechanical steps. Comparing Figures 5a) and 5b), it is shown, for this $\mathrm{Fe}-27 \% \mathrm{Co}$ alloy, that annealing Goss texture is all the more strong that the $\{111\}<112\rangle$ component is intense at the preceding cold rolling state. This is in agreement with results of the literature on single (or poly) crystal(s) of Fe-Si alloy [4, 11], where it has been considered that the $\{111\}<112>$ intensity is at the origin of the Goss development during the primary recrystallization. This point will be discussed below.

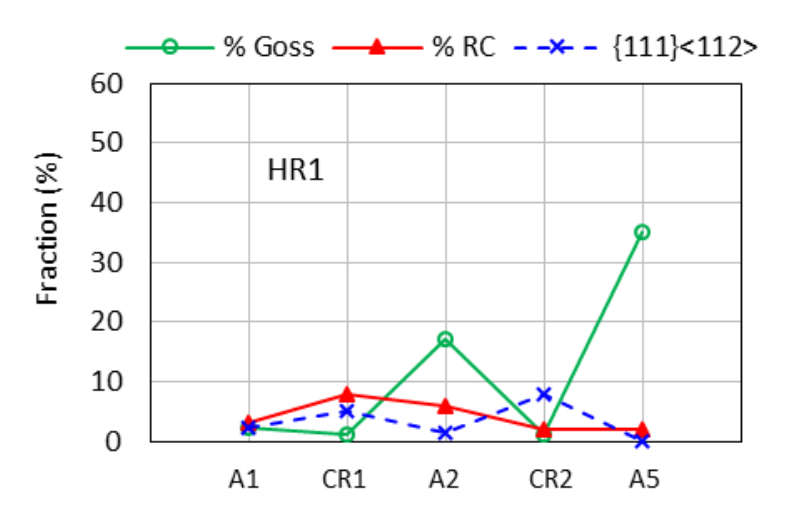

(a)

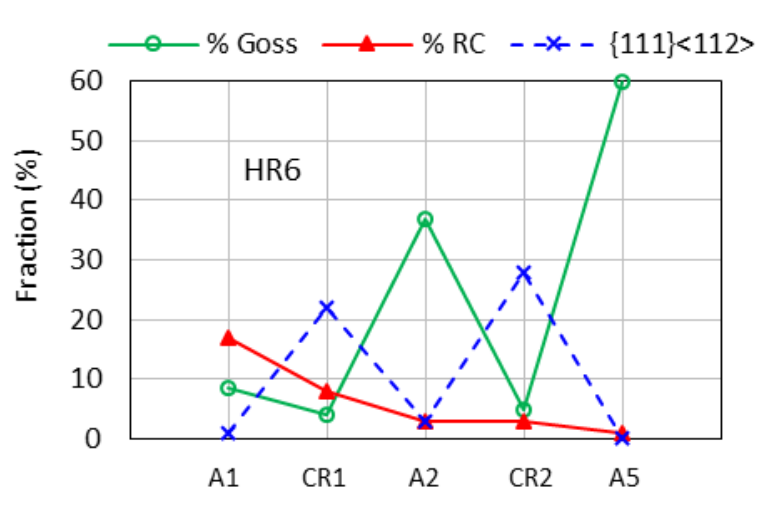

(b)

Figure 5: Evolution of the main texture components during the thermo-mechanical processing of the hot rolled sheet (a) HR1 and (b) HR6

Since the final Goss fraction depends on the $\{111\}<112\rangle$ intensity, the origin of the $\{111\}<112>$ after cold rolling has been investigated in previous works in Fe-Co alloys [17]. It has been shown that during cold rolling, Goss crystals can rotate by $35^{\circ}$ around the transverse direction to form the $\{111\}<112>$ crystals and that rotated Cube grains can rotate by $55^{\circ}$ around TD to become $\{111\}<112>$ grains. Both Goss and rotated Cube orientations have then a crucial position to promote $\{111\}<112>$ formation during cold rolling. Proofs are given in Figure 5a) where a too small amount of Goss and rotated Cube $(<5 \%)$ at the initial stage (A1) puts in danger the $\{111\}<112>$ formation during CR1 and thus weakens the final Goss amount (A5). On the contrary, initial fractions of Goss and rotated Cube greater than $9 \%$ ensure the $\{111\}<112>$ development during CR1 and lead to a high final Goss fraction $(60 \%)$.

The aim of the present work is to determine which hot rolling conditions favor the Goss development during the thermo-mechanical process of $\mathrm{Fe}-27 \% \mathrm{Co}$ sheet elaboration. The final Goss development has been associated to the non-neglecting fraction of Goss and rotated Cube at the A1 stage. Because hot rolling conditions for HR1 and HR6 were not provided, then, it has been decided to elaborate four new samples (HR2 to HR5), changing hot rolling temperatures, in order to reproduce the typical magnetic inductions of samples HR1 and HR6 (Figure 1). The goal is to deduce the unknown conditions and to find the best ones to optimize magnetic properties.

These magnetic properties have been successfully reproduced for samples HR2 (close to HR1) and HR5 (close to HR6) (Figure 1). Corresponding microstructures and textures are described in Figure 6 . The HR2 hot rolling has been entirely performed in the austenitic phase $\left(>930^{\circ} \mathrm{C}\right)$ whereas the HR5 hot rolling has been finished at a lower temperature (around $760^{\circ} \mathrm{C}$ ) in the ferritic domain. HR3 and HR4 correspond to intermediate conditions that will not be detailed in the present study. 

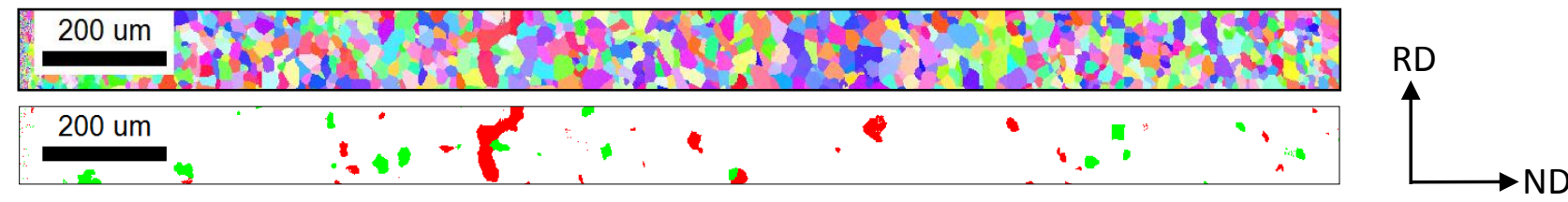

(a)
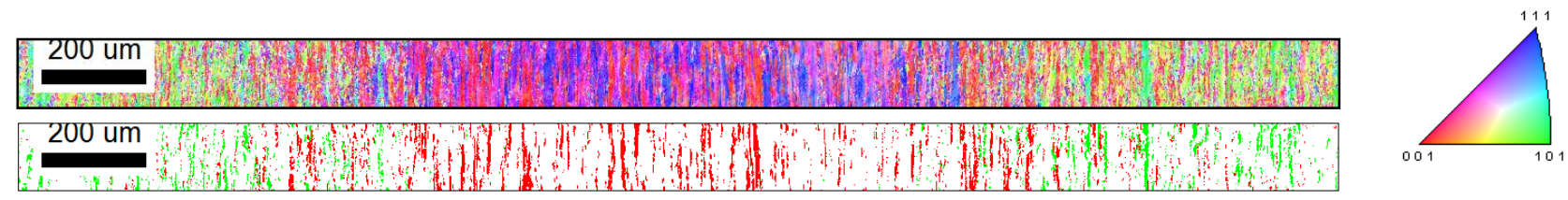

(b)

Figure 6: Hot rolling microstructures of (a) austenitic hot rolling HR2 and (b) ferritic hot rolling HR5. Upper map : ND-IPF map, lower map : Rotated Cube (red) and Goss (green)

Figure 6 shows that the microstructure strongly depends on the hot rolling conditions. In the case of the austenitic hot rolling (HR2), microstructure is quite homogeneous and recrystallized through the thickness (Figure 6a) and texture is weak. On the contrary, when hot rolling is finished in the ferritic phase (HR5), the microstructure is still deformed. As desired, a high texture heterogeneity is obtained through the thickness ( $\mathrm{t}$ ) of HR5 with a high fraction of rotated Cube (Figure 6b) in the mid-thickness $(15 \%(0.3 \%$ Goss $))$ and a noticeable Goss orientation at the sheet surface over a distance of $\mathrm{t} / 4$ at each side (11\% (4\% rotated Cube)). Because of the good magnetic induction of HR5 (Figure 1), it can be assumed that the final Goss fraction (after A5) is high. This is not surprising since there is already, at the hot rolled state, a high quantity of Goss and rotated Cube necessary to develop the $\{111\}<112>$ during cold rolling and thus to guaranty an intense Goss at the end of the thermomechanical process (A5) (case of Figure 5b).

To sum up, ending the hot rolling at a temperature below the austenite/ferrite transformation seems to guaranty the Goss and rotated Cube formation during hot rolling and then ensures good magnetic induction properties for the final product. As proposed by Butron-Guillen and Jonas [16] in IF steels, when the finishing rolling temperature is in the austenite temperature range, the Cube texture forms in the austenite phase and is converted, during the ferritic transformation, into the rotated Cube, Goss and rotated Goss orientations. For the Fe-27\% Co alloy, these three first components are observed but in low quantities (about 3\%). Butron-Guillen and Jonas [16] showed that when the rolling is finished in the ferritic range, after the transformation starts, the texture is more intense $\left(\mathrm{ODF}_{\max }=13\right.$ against 5 for HR2), and apart from marked Goss and rotated Cube, it also contains the typical $\alpha$ and $\gamma$ fibers encountered in bcc cold rolled materials. In agreement, in the present work, the $\alpha$ and $\gamma$ fibers are quite developed in HR5 (20 and 15\% respectively). The role of the finishing rolling temperature is then crucial as far as texture is concerned.

As it was already shown in Figure 6, comparing to HR2 and HR5, the hot rolling performed in the ferritic domain (HR5) develops higher intensity of Goss grains in areas in contact with the rolling mills. This can be attributed to the higher shear rate induced by the low hot rolling temperature.

To explain this trend at low temperature, it could be assumed that during the hot rolling, the high deformation rate (shearing plus compression) at the surface of the hot rolled sheet, results in the creation of numerous shear bands. Inside these bands, the local shear will induce the creation of nuclei of the Goss orientation [17-19] and subsequently by dynamic recrystallization, these Goss grains will grow into the matrix at the expense of the $\gamma$ fiber. Actually, this phenomenon of Goss nucleation inside shear bands has been observed, not during hot rolling because the dynamic kinetic makes it difficult to catch, but during static recrystallization after cold rolling. Figure 7a shows the presence of shear bands located inside the $\{111\}<112>$ cold rolled grains. Goss sub-grains of $1 \mu \mathrm{m}$ diameter are identified inside these shear bands (Figure 7b). For high rates of reduction in the Fe-Si, Dorner et al. [20] 
explained the formation of these new Goss grains in shear bands by the effect of the local shearing which implies a sudden rotation of the $\{111\}<112>$ component into the Goss one.

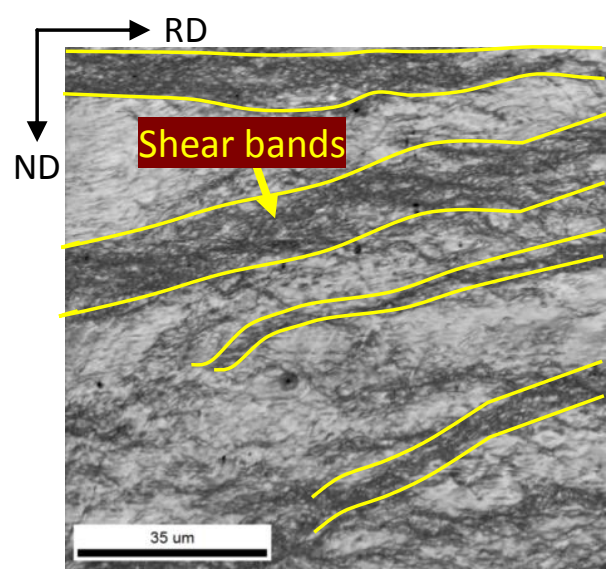

(a)

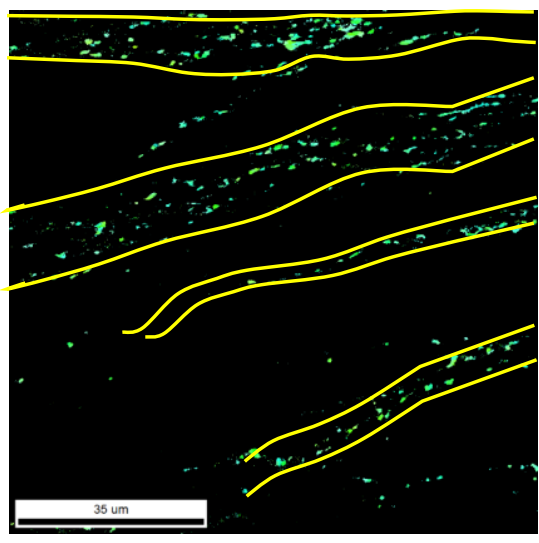

(b)

Figure 7: Cold rolled grains having the $\{111\}<112>$ orientation with shear bands containing Goss sub-grains. (a) Distribution of the image quality parameter (that describes the quality of an electron backscatter diffraction pattern) with a step of 0.1 microns and (b) pixels belonging only to Goss orientation (green).

Sample HR5 after second cold rolling CR2.

During the primary recrystallization, occurring during the subsequent annealing treatments A3 to A5, the Goss texture, present in the shear bands of the $\{111\}<112\rangle$ grains, develops at the expense of this last orientation [13]. This development, which occurs by Strain Induced Boundary Migration (SIBM) [21], is related to the stored energy gap, measured at the cold rolling state, between the Goss sub-grains and the surrounding $\{111\}<112>$ matrix. The stored energy was estimated by ESBD using the KAM parameter (Kernel Average Misorientation) [22]. This last parameter was calculated with a kernel size of 1 micron excluding the misorientation greater than $5^{\circ}$. Figure 8 shows the KAM values for $\{111\}<112>$ grains and for their associated Goss sub-grains inside shear bands.

The Goss sub-grains exhibit lower energy (Figure 8) than the surrounding matrix, which explains their recrystallization at the expense of the $\{111\}<112>$ component, during annealing [23].

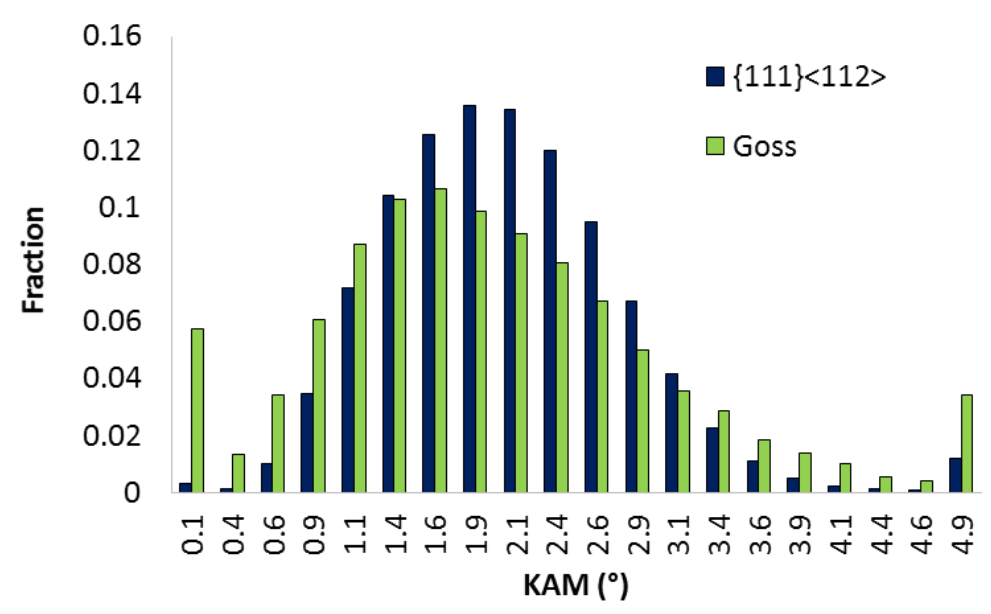

Figure 8: Distribution of KAM parameter for Goss sub-grains in shear bands and surrounding $\{111\}<112>$ grains. Sample HR5 after the second cold rolling CR2. 


\section{Conclusion}

The Goss formation during thermo-mechanical processing of the advanced Fe-27\%Co alloy has been studied.

The hot rolling conditions are determinant to obtain a large amount of Goss orientation in the final product. The presence of Goss and rotated Cube at the rolling stage guaranty the Goss development during the entire process.

A low temperature at the end of hot rolling allows large shear deformation, especially induced by mill rolls contact, at the origin of shear bands. Goss nuclei are formed inside these shear bands. During further annealing treatments, these nuclei grow at the expense of the surrounding matrix, since the Goss nuclei have lower stored energy and thus have an advantage to grow by strain induced boundary migration.

A hot rolling ending in the ferritic phase implies higher shearing and then higher intensity of the final Goss texture.

From an industrial point of view, applying a hot rolling in the ferritic domain will induce an enhancement of the magnetic properties of the product.

\section{Acknowledgements}

The authors acknowledge 'La region Ile de France' for the funding of the 3MT project.

\section{References}

[1] N. Bernier, E. Leunis, C. Furtado, T. Van De Putte, G. Ban, EBSD study of angular deviations from the Goss component in grain-oriented electrical steels, Micron. 54-55 (2013) 43-51. doi:10.1016/j.micron.2013.08.003.

[2] C. Sun, Y.H. Sha, F. Zhang, L. Zuo, Effect of Single Pass Hot Rolling on Goss Texture Development in Twin-Roll Cast Silicon Steel Strip, in: Adv. Manuf. Sci. Eng., Trans Tech Publications, 2013: pp. 78-81. doi:10.4028/www.scientific.net/AMR.712-715.78.

[3] H.E. Goss U.S. Patent No. 2,025,814. Washington, DC (1935)

[4] C. Gheorghies, A. Doniga, Evolution of Texture in Grain Oriented Silicon Steels, J. Iron Steel Res. Int. 16 (2009) 78-83. doi:10.1016/S1006-706X(09)60065-0.

[5] A. Böttcher, K. Lücke, Influence of subsurface layers on texture and microstructure development in RGO electrical steel, Acta Metall. Mater. 41 (1993) 2503-2514. doi:10.1016/0956-7151(93)90331-L.

[6] C.H. Han, J.C. Shin, Rolled textures and magnetic properties of regular grain oriented 3\% silicon steel with very low thickness, Proceedings of ICOTOM 9, Avignon (France), 14-18 (1991) 915-920.

[7] S. Mishra, C. Därmann, K. Lücke, On the development of the goss texture in iron-3\% silicon, Acta Metall. 32 (1984) 2185-2201. doi:10.1016/0001-6160(84)90161-5.

[8] A. Samet-Meziou, A.L. Etter, T. Baudin, R. Penelle, Recovery and recrystallization study after low deformation amount by cold rolling in an IF-Ti steel, 2004.

[9] Y. Inokuti, Y. Shimizu, C. Maeda, H. Shimanakai Transmission Kossel study of the structure during secondary recrystallization in grain oriented silicon steel, Proceedings of the 1st Riso Intenational Symposium on Metallurgy and materials sciences (1980) 71-76.

[10] A. Sakakura, S. Taguchi, Effects of AlN on secondary recrystallization textures in cross rolled and annealed (001) (hkl) oriented single crystals of pct Si-Fe. Metall. Trans. 2 (1971) 205-. doi:10.1007/BF02662659.

[11] J.L. Walter, C.G. Dunn, An effect of impurity atoms on the energy relationship of (100) and (110) surfaces in high purity silicon iron. Acta Metall. 8 (1960) 497-503. doi:10.1016/00016160(60)90102-4.

[12] D. Dorner, S. Zaefferer, L. Lahn, D. Raabe, Overview of Microstructure and Microtexture Development in Grain-oriented Silicon Steel, J. Magn. Magn. Mater. 304 (2006) 183-186. doi:10.1016/j.jmmm.2006.02.116. 
[13] F. Cruz-Gandarilla, R. Penelle, T. Baudin et al. Texture and microstructure evolution in a Fe-Si CGO sheet during the processing route before the secondary recrystallization, ICOTOM 15 , Pittsburgh, Pennsylvania, USA, June 1-5 2008, Ceramic Transactions, 200 (2009) 123-130.

[14] F. Cruz-Gandarilla, R. Penelle, H.M. Leon, T. Baudin, J.G. Cabañas-Moreno, A study of local microstructure and texture heterogeneities in a CGO Fe3\%Si alloy from hot rolling to primary recrystallization, in: Mater. Sci. Forum, (2005) 483-488.

[15] D. Vanderchueren, L. Kestens, P. Van Houtte, E. Aernoudt, J. Dilewijns, U. Meers. Influence of transformation induced recrystallisation on hot rolling textures of low carbon steel sheet. Mater. Sci. Technol. 6 (1990) 1247-1250. doi:10.1179/mst.1990.6.12.1247.

[16] M.P. ButronGuillen, J.J. Jonas, Effect of finishing temperature on hot band textures in an IF steel, ISIJ Int. 36 (1996) 68-73. doi:10.2355/isijinternational.36.68.

[17] B. Nabi. Nouveaux alliages Fe-Co magnétiques pour l'aéronautique, à microstructure partiellement recristallisée et à texture fortement orientée, Ph.D. thesis, University of Paris-Sud (2014).

[18] L.F. Shuai, T.L. Huang, G.L. Wu, X. Huang, O. V. Mishin, Development of Goss texture in $\mathrm{Al}-0.3 \% \mathrm{Cu}$ annealed after heavy rolling, J. Alloys Compd. 749 (2018) 399-405. doi:10.1016/j.jallcom.2018.03.187.

[19] H.T. Jiao, Y.B. Xu, L.Z. Zhao, R.D.K. Misra, Y.C. Tang, M.J. Zhao, D.J. Liu, Y. Hu, M.X. Shen, Microstructural evolution and magnetic properties in strip cast non-oriented silicon steel produced by warm rolling, Mater. Charact. (2019). doi:10.1016/j.matchar.2019.109876.

[20] D. Dorner, S. Zaefferer, D. Raabe, Retention of the Goss orientation between microbands during cold rolling of an Fe3\%Si single crystal, Acta Mater. 55 (2007) 2519-2530. doi:10.1016/j.actamat.2006.11.048.

[21] F.J. Humphreys, M. Hatherly. Recrystallization and Related Annealing Phenomena, 2nd Edition, Elsevier (2004).

[22] S.I. Wright, D.P. Field, D.J. Dingley. Electron Backscatter Diffraction in Materials Science, Eds. A. J. Schwartz, M. Kumar and B.L. Adams, chapter 13. (2000).

[23] A.L. Etter, T. Baudin, R. Penelle, Influence of the Goss grain environment during secondary recrystallisation of conventional grain oriented Fe-3\%Si steels, Scr. Mater. 47(11) (2002) 725730. doi:10.1016/S1359-6462(02)00189-6. 